\title{
The Roles of Lpar1 in Central Nervous System Disorders and Diseases
}

\author{
Dongqiong Xiao ${ }^{1,2}$, Xiaojuan $\mathrm{Su}^{1}, \mathrm{Hu} \mathrm{Gao}^{2}$, Xihong $\mathrm{Li}^{2 *}$ and $\mathrm{Yi} \mathrm{Qu}^{1 *}$ \\ ${ }^{1}$ Key Laboratory of Birth Defects and Related Diseases of Women and Children, Department of Pediatrics, Ministry \\ of Education, West China Second University Hospital, Sichuan University, Chengdu, China, ${ }^{2}$ Key Laboratory of Birth Defects \\ and Related Diseases of Women and Children, Department of Emergency, Ministry of Education, West China Second \\ University Hospital, Sichuan University, Chengdu, China
}

\section{OPEN ACCESS}

Edited by:

M. Chiara Manzini,

Rutgers, The State University

of New Jersey, United States

Reviewed by:

Marco Santorelli,

Italian Institute of Technology (IIT), Italy

Ashwin S. Shetty,

Harvard University, United States

*Correspondence:

Xihong Li

lixihonghxey@163.com

Yi Qu

quyi712002@163.com

Specialty section:

This article was submitted to

Neurodevelopment,

a section of the journal

Frontiers in Neuroscience

Received: 16 May 2021

Accepted: 09 July 2021

Published: 27 July 2021

Citation:

Xiao D, SuX, Gao H, Li X and Qu Y (2021) The Roles of Lpar1 in Central Nervous System Disorders

and Diseases.

Front. Neurosci. 15:710473.

doi: 10.3389/fnins.2021.710473
Lysophosphatidic acid receptor 1 (Lpar1), which is found in almost all human tissues but is most abundant in the brain, can couple to G protein-coupled receptors (GPCRs) and participate in regulating cell proliferation, migration, survival, and apoptosis. Endothelial differentiation gene-2 receptor (Edg2), the protein encoded by the Lpar1 gene, is present on various cell types in the central nervous system (CNS), such as neural stem cells (NSCs), oligodendrocytes, neurons, astrocytes, and microglia. Lpar1 deletion causes neurodevelopmental disorders and CNS diseases, such as brain cancer, neuropsychiatric disorders, demyelination diseases, and neuropathic pain. Here, we summarize the possible roles and mechanisms of Lpar1/Edg2 in CNS disorders and diseases and propose that Lpar1/Edg2 might be a potential therapeutic target for CNS disorders and diseases.

Keywords: Lpar1, Edg2, astroglia, microglia, oligodendrocyte, astrocyte

\section{INTRODUCTION}

Lysophosphatidic acid receptor 1 (Lpar1) was first discovered in the developing brain in 1996 (Hecht et al., 1996). It was found to be enriched in the ventricular zone (VZ) of the embryonic cerebral cortex. Then, five other receptors of the Lpar family, including Lpar2, Lpar3, Lpar4, Lpar5, and Lpar6, were characterized, and they were all found to be expressed in the central nervous system (CNS) (Choi et al., 2010). These receptors are cell surface G protein-coupled receptors

Abbreviations: AD, Alzheimer's disease; AJs, adherens junctions; 2ccPA, 2-O-carba-cyclic phosphatidic acid; 5-HT, 5hydroxytryptamine; BDNF, brain-derived neurotrophic factor; CNS, central nervous system; ceRNA, competing RNA; EAE, experimental autoimmune encephalomyelitis; EB3, third E-boxes; Edg2, endothelial differentiation gene-2 receptor; DG, dentate gyrus; DRG, dorsal root ganglion; FGFR, fibroblast growth factor receptor; FRS $2 \alpha$, FGFR substrate $2 \alpha$; GA, Golgi apparatus; GABA, $\gamma$-aminobutyric acid; GDNF, glial cell line derived neurotrophic factor; GPCRs, G protein-coupled receptors; HBO, hyperbaric oxygen; HD, Huntington's disease; HEB, HeLa E-Box binding protein; Keap1, Kelch like ECH associated protein 1; LPA, lysophosphatidic acid (1-acyl-sn-glycerol-3-phosphate); Lpar1, lysophosphatidic acid receptor 1; LE/Lys, late endosomes/lysosomes; lncRNAs, long non-coding RNAs; MAPK, mitogen-activated protein kinase; MBP, myelin basic protein; MOG, myelin oligodendrocyte glycoprotein; MS, multiple sclerosis; MMPs, matrix metalloproteinases; NPCs, neural progenitor cells; NGF, nerve growth factor; Nrf2, nuclear factor erythroid 2-related factor 2; OPCs, oligodendrocyte precursor cells; P2, postnatal day 2; pre-OLs, premyelinating oligodendrocytes; PHH, posthemorrhagic hydrocephalus; PLP, proteolipid protein; RER, rough endoplasmic reticulum; ROS, reactive oxygen species; RE, recycling endosomes; SGZ, subgranular zone; SNAREs, soluble N-Ethylmaleimide-sensitive factor attachment protein receptors; SGM, somatic genomic mosaicism; TBI, traumatic brain injury; TNF, tumor necrosis factor; V-SVZ, ventricular-sub-ventricular zone; WMI, white matter injury; 4E-BP1, 4E-binding protein. 
(GPCRs), and their ligand is lysophosphatidic acid 1-acylsn-glycerol-3-phosphate (LPA). Many potential roles for LPA and LPA receptor signaling have been reported; LPA and LPA receptors are mediated by second messenger pathways after coupling to the $\mathrm{G}$ proteins, Gi/0, Gaq, and G12/13 and participate in the regulation of cell proliferation, migration, survival, apoptosis, and morphology (Panetti, 2002; Takuwa et al., 2002; de San Roman et al., 2015; Figure 1).

\section{CHARACTERISTICS OF Edg2}

Endothelial differentiation gene-2 receptor (Edg2) is encoded by Lpar1, which is found in almost all human tissues but is most abundant in the brain (An et al., 1997). Human Edg2 is a 364-amino acid protein with a putative nuclear translocation signal, an $\mathrm{N}$-terminal acidic domain, and a cysteinerich C-terminal domain containing a putative zinc finger structure (Hla et al., 1995; An et al., 1997; Allard et al., 1999). The polypeptide sequence of Edg2 was highly conserved during evolution, suggesting that it may be an important regulator of general nuclear function (Hla et al., 1995). Edg2 is a seventransmembrane domain receptor with high specificity for LPA (Erickson et al., 1998). Edg2 is present on various cell types, such as astrocytes, oligodendrocytes, microglia, and neurons, in the CNS (Allard et al., 1999; Yung et al., 2015; Figure 2). Edg2 can induce cellular proliferation and morphological changes. It has been proposed to be involved in many physiological and pathological processes, including neurogenesis, myelination, angiogenesis, wound healing, and cancer progression (Allard et al., 1999; Contos J.J. et al., 2000; Yung et al., 2015). Edg2 can efficiently couple to the yeast heterotrimeric G-protein in response to LPA binding and activate the yeast mitogenactivated protein kinase (MAPK) pathway (Erickson et al., 1998; Choi et al., 2010). Edg2 can also couple with Gi/o to activate Ras and then the MEK-ERK pathway. Subsequently, ERK acts to inhibit the tuberous sclerosis complex (TSC1/2), thereby increasing GTP loading on Ras homolog enriched in brain (Rheb) and thus activating mTORC1. mTORC1 then phosphorylates downstream targets, such as S6K1 and eukaryotic initiation factor 4E-binding protein (4E-BP1), ultimately leading to increased mRNA translation (Winter et al., 2010; Figure 3). Lpar1 with the P308S, I310T, and $\mathrm{Y} 311 \mathrm{H}$ mutations might not interact with helix 8, which corresponds to codons 315-326 of Lpar1, leading to structural defects and retention of Edg2 in the endoplasmic reticulum (ER). In addition, mutation of Lpar1 can alter its intracellular activities, such as $\mathrm{Ca}^{2+}$ mobilization, inhibition of cAMP formation, and cytoskeletal changes, which are mainly mediated by Gq, Gi/o, and G12/13, respectively (Ishii et al., 2017). Lpar1 deletion can cause neurodevelopmental disorders and CNS diseases, including brain cancer, neuropsychiatric disorders, demyelination diseases, and neuropathic pain (Table 1).

\section{DISTRIBUTION OF Edg2}

Information about Edg2 distribution was obtained from in situ hybridization studies. Edg2 is expressed in most mammalian cells and tissues. In the brain, Edg2 appears to be localized within specific brain regions and in certain cell types.

In the rodent embryonic cortex, Lpar1 mRNA is predominately present in the neurogenic VZ (Hecht et al., 1996; Allard et al., 1998). Lpar1 mRNA is first detected on postnatal day 2 (P2) in the medulla oblongata and cervical spinal cord and is observed in the deep white matter of the cerebellum and brainstem on postnatal day 14 (P14) (Stankoff et al., 2002). However, in adults, Edg2 receptor mRNAs are restricted to white matter tracts (Handford et al., 2001; Stankoff et al., 2002). This phenomenon was also reported in another study. Functional $\left.{ }^{35} \mathrm{~S}\right] \mathrm{GTP} \gamma \mathrm{S}$ autoradiography revealed that Lpar1/Edg2 binding sites were observed in myelinated areas of the white matter, such as the corpus callosum, internal capsule and cerebellum, in the brains of adult rodent and humans (de San Roman et al., 2015). Many cells in the brain, such as neural stem cells (NSCs), oligodendrocytes, neurons, astrocytes, and microglia, can express Lpar1/Edg2.

\section{FUNCTIONS OF Edg2}

\section{Edg2 in NSCs}

Neural stem cells are multipotent cells that can generate radial glia, oligodendrocyte progenitor cells (OPCs), neurons, and astrocytes (Urbán et al., 2019). In rodents, NSCs are found in the sub-granular zone (SGZ) of the dentate gyrus (DG) in the hippocampus and ventricular-sub-ventricular zone (V-SVZ) lining the lateral ventricles (Yao et al., 2012; Urbán et al., 2019). NSC maintenance, division, and differentiation are controlled by multiple genes and steps. Any alteration in the program that regulates genes may disrupt NSC maintenance, division, and differentiation.

LPA-Lpar1 signaling may enhance NSC differentiation. Lpar1/Edg2 is expressed on embryonic NSCs. LPA-Lpar1 signaling increases non-vertical cleavage of apical progenitor cells and enhances the differentiation of progenitors into intermediate progenitor cells (McDonald et al., 2020).

McDonald et al. (2020) reported that LPA-Lpar1 signaling influences NSC cleavage plane orientation and early cell fate. LPA-Lpar1 signaling alters NSC cleavage plane orientation by disrupting cellular adherens junctions (AJs), leading to premature neurogenesis. Enhanced LPA-Lpar1 signaling has been shown to enhance neurogenesis and decrease programmed cell death. Intermediate neural progenitor cells (NPCs) expressing T-box brain protein 2 (Tbr2) are typically localized to the cortical plate during early to mid-neurogenesis. LPA-Lpar1 signaling increases the number of Tbr2 ${ }^{+}$cells, suggesting that LPA-Lpar1 signaling-induced cleavage plane abnormalities may trigger an increase in the Tbr2 ${ }^{+}$cell number. An increase in the number of Tbr $2^{+}$cells indicates aversion of programmed cell death through premature cell cycle exit and neuronal differentiation (Kingsbury et al., 2003; McDonald et al., 2020).

\section{Edg2 in Oligodendrocytes}

Oligodendrocytes are myelin-forming cells in the CNS. Myelin sheaths are formed by oligodendrocytes, which wrap axons 


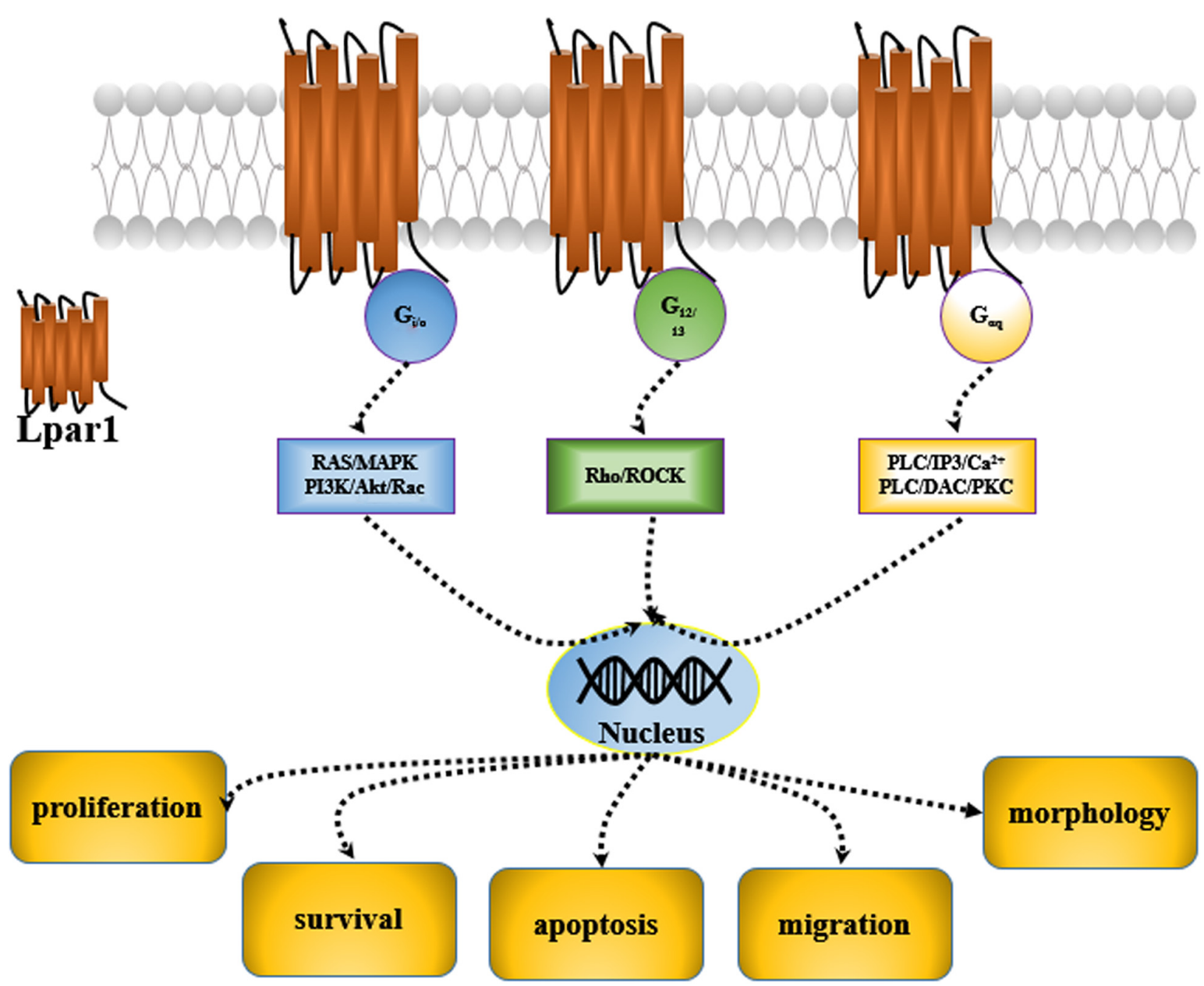

FIGURE 1 | LPA signaling causes G proteins to play different roles in the CNS.

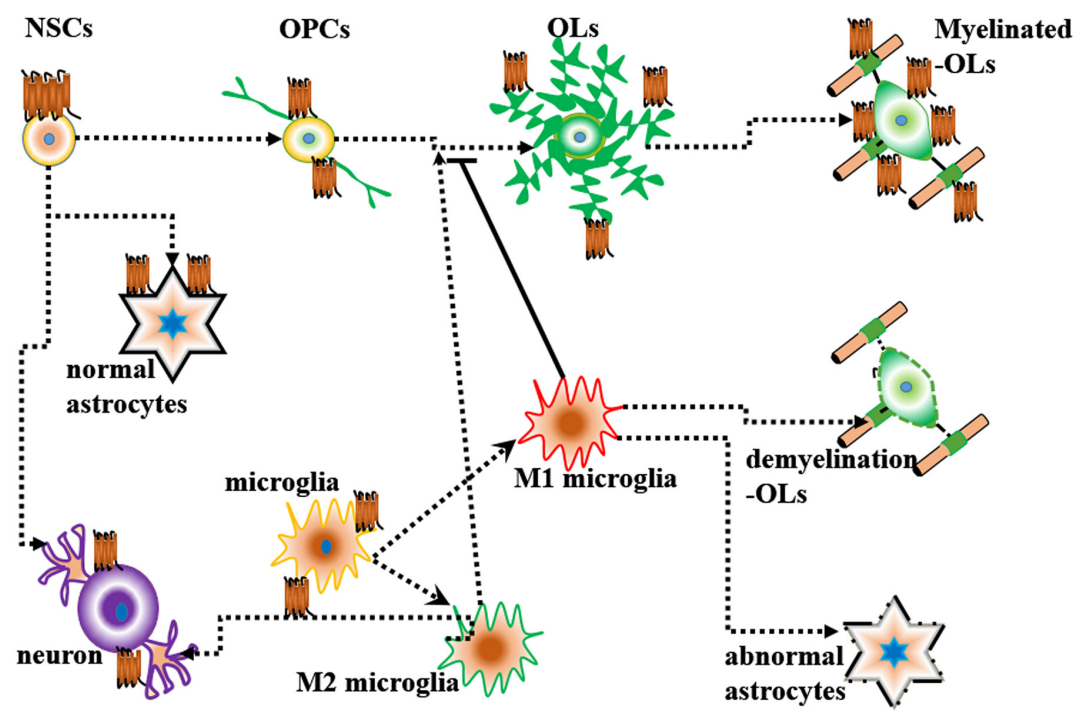

FIGURE 2 | Lpar1/Edg2 is present on various cell types and interacts with glial cells and neurons. 


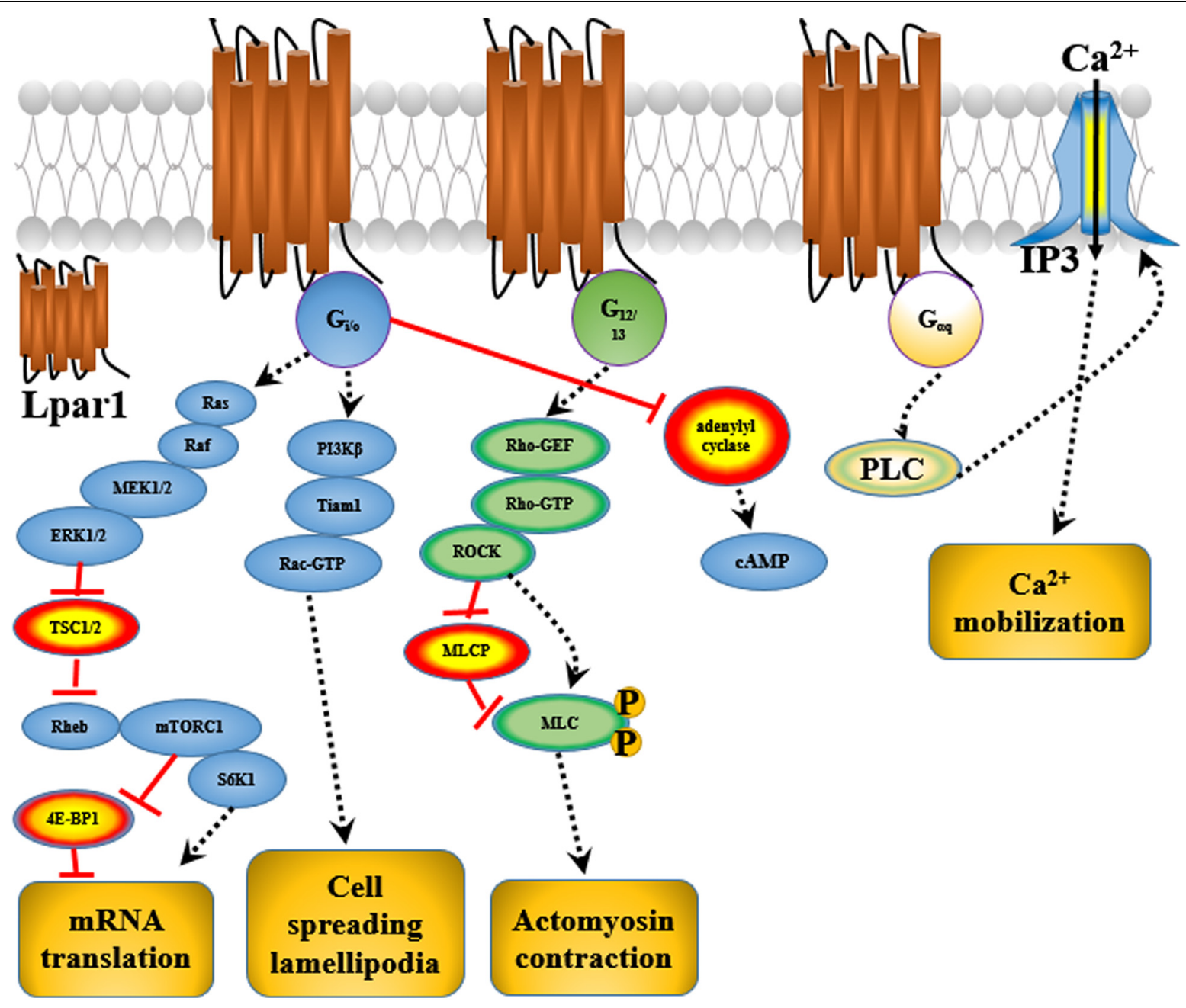

FIGURE 3 | The possible mechanisms by which Lpar1 exerts its effects in glial and neuronal cells.

during late fetal and early postnatal stages (Piaton et al., 2010). Differentiation of NSCs into oligodendrocytes occurs in multiple stages and is controlled by differentiation-regulated transcription factors, which are stage-specific markers (White and Kraemer-Albers, 2014; Czepiel et al., 2015; Goldman and Kuypers, 2015). During development, mature oligodendrocytes originate from NSCs that are generated in discrete areas of the CNS and migrate to their destination to differentiate into post-migratory oligodendrocytes, OPCs, pre-myelinating oligodendrocytes (pre-OLs) and mature oligodendrocytes in a cell autonomous fashion (Bradl and Lassmann, 2010; Czepiel et al., 2015; Domingues et al., 2016). A key step controlling whether OPCs/pre-OLs adopt a myelinating fate is specific axon-glia recognition (White and Kraemer-Albers, 2014). Myelin biogenesis requires intricate membrane sorting and trafficking machinery following axon recognition and positioning of myelination-competent oligodendrocytes as well as directed vesicular trafficking pathways. Proteolipid protein (PLP) mRNA is translated in the rough endoplasmic reticulum (RER) of the cell body, packed into vesicles in the Golgi apparatus
(GA), and transported to peripheral myelin (Bauer et al., 2002). PLP endocytosis and recycling to the plasma membrane are regulated by soluble $\mathrm{N}$-ethylmaleimide-sensitive factor attachment protein receptors (SNAREs); PLP is recycled by recycling endosomes (REs) via a VAMP3-dependent pathway and by late endosomes (LEs)/lysosomes (Lys) via a VAMP7dependent pathway (Feldmann et al., 2011; White and KraemerAlbers, 2014; Figure 4). Impaired trafficking of PLP from the ER and GA to the plasma membrane leads to oligodendrocyte apoptosis and demyelination (Bauer et al., 2002; Feldmann et al., 2011).

The Lpar1/Edg2 receptor is expressed in OPCs and mature oligodendrocytes in the postnatal rat brain (Nogaroli et al., 2009; Garcia-Diaz et al., 2015). Lpar1/Edg2, which is expressed on the oligodendrocyte cell membrane and oligodendrocyte processes and co-localizes with myelin basic protein (MBP), plays crucial roles in regulating oligodendrocyte migration, survival, apoptosis, morphology, and myelination.

First, Lpar1/Edg2 can regulate OPC migration. LPA-Lpar1 signaling activates downstream Rho-ROCK and stimulates 


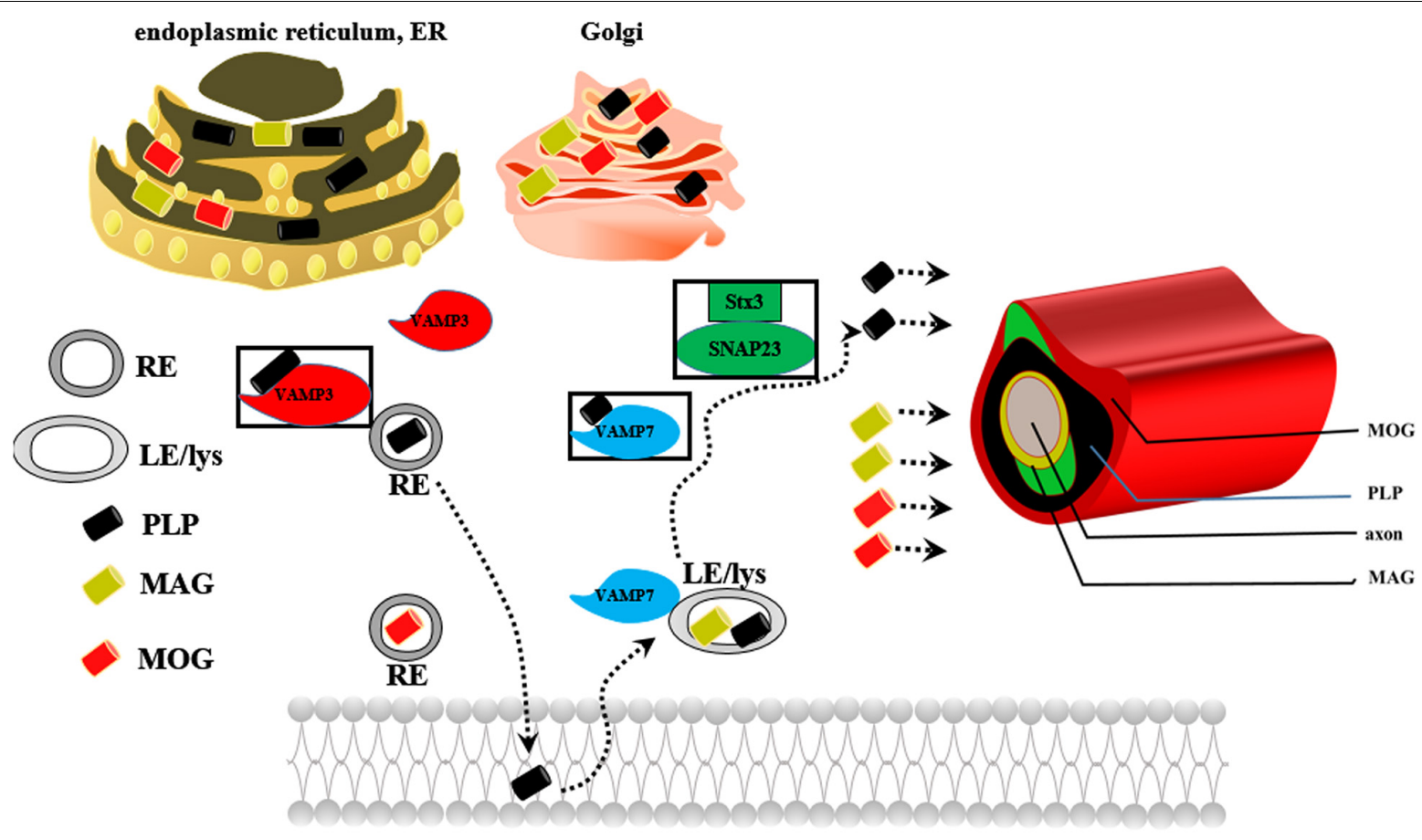

FIGURE 4 | The possible mechanism underlying the role of PLP in myelin biogenesis. REs, recycling endosomes; LEs/Lys, late endosomes/lysosomes.

actomyosin contraction in OPCs, thus modulating OPC migration to specific regions of the brain (Dawson et al., 2003).

Second, Lpar1/Edg2 can regulate oligodendrocyte survival and apoptosis. Matsushita et al. (2005) found that Lpar1/Edg2 is expressed in the immortalized oligodendrocyte cell line OLP6. OLP6 cell apoptosis was shown to be induced upon serum withdrawal, and this apoptosis was shown to be inhibited by the addition of $5 \%$ serum or $10 \mu \mathrm{M}$ LPA, a Lpar1/Edg2 ligand, to the serum-free medium. These results indicate that the activation of LPA-Lpar1 signaling plays an anti-apoptotic role in oligodendrocytes, enhancing the survival of immature oligodendrocytes.

Third, Lpar1/Edg2 can regulate oligodendrocyte morphology. Lpar1/Edg2 was detected in O4-positive cells with processes with both simple and complex morphologies (Nogaroli et al., 2009). The effect of LPA-Lpar1 on oligodendrocyte morphology may be associated with cytoskeletal rearrangements, which are involved in the outgrowth of oligodendrocytes for membrane sheath formation (Nogaroli et al., 2009). The absence of Lpar1/Edg2 leads to fiber disorganization and alterations in morphology via an increase in the number of unmyelinated axons and the myelin g-ratio (Garcia-Diaz et al., 2015).

Finally, Lpar1/Edg2 can enhance oligodendrocyte differentiation and myelination. Matsushita et al. (2005) found that when LPA binds to Lpar1/Edg2 expressed in immortalized oligodendrocyte cells (OLP6 cells), Gi/o is activated, leading to phosphorylation of $\mathrm{p} 44 / \mathrm{p} 42 \mathrm{MAPK}$, inhibition of adenylyl cyclase, thus promotion of the differentiation of OPCs into immature OLs and then into mature OLs. Stankoff et al. (2002) observed that Lpar1/Edg2 is selectively expressed in mature post mitotic oligodendrocytes prior to myelination, contributes to the latest stages of oligodendrocyte maturation, and may be involved in myelination. LPA increases the number of cells positive for MBP but not myelin oligodendrocyte glycoprotein (MOG), which implies that LPA may play a crucial role in regulating the later stages of oligodendrocyte maturation (Nogaroli et al., 2009). Myelin biogenesis involves translation of PLP mRNA in the RER, sorting of PLP components in the trans-GA, and subsequent transport of these components to the plasma membrane by endocytic recycling. Dysfunction of any of these processes leads to retention of PLP in the RER or GA and initiation of myelin diseases characterized by developmental hypomyelination and demyelination. Indeed, Lpar1 activation has been associated with vesicle-mediated endocytosis (Nogaroli et al., 2009), which participates in PLP trafficking, oligodendrocyte maturation and myelination. A lack of the Lpar1 receptor results in accumulation of myelin PLP in the RER, causes PLP protein to be trapped within the RER, and causes anomalous trafficking of PLP, suggesting stress-induced apoptosis of oligodendrocytes and disruption of PLP endocytosis and recycling to the plasma membrane (Garcia-Diaz et al., 2015). We speculate that Lpar1/Edg2 may participate in PLP trafficking, thus leading to oligodendrocyte maturation and later myelination.

\section{Edg2 in Neurons}

Cortical neurogenesis, during which NPCs/NSCs differentiate into glial progenitors and young post-mitotic neurons, occurs from E10-18 in mice. Mature neurons establish polarity through neurite specification and develop axons and dendrites (Yung et al., 2015). The interaction between axons and glia is 
programmed, and disorders affecting this interaction may lead to demyelinating diseases or neuropathic pain.

Lysophosphatidic acid receptor 1/Endothelial differentiation gene-2 receptor is expressed on dorsal root ganglion (DRG) neurons (Pan et al., 2016) and hippocampal neurons (Park et al., 2015), which regulates neuronal morphology, motility, growth cone collapse, calcium signaling, and proliferation. LPA has been reported to induce necrosis and apoptosis of hippocampal neurons (Park et al., 2015). Lpar1/Edg2 activation can increase the excitability of hippocampal neurons. This increase in neuronal excitability seems to be associated with gintonin-induced Lpar1/Edg2 activation via the phospholipase C (PLC)-dependent signaling pathway and voltage-gated potassium (Kv) channels (Park et al., 2015). Gintonin-mediated Lpar1/Edg2 activation is associated with N-methyl-D-aspartic acid (NMDA) receptors and consequently increased synaptic transmission (Park et al., 2015). Gintonin increases the transient $\mathrm{Ca}^{2+}$ current through Lpar1/Edg2 activation (Park et al., 2015). The neuroprotective molecular mechanisms of gintonin are mediated through multiple processes, including anti-oxidative stress, an increase in brain-derived neurotrophic factor (BDNF) and Sirtl expression, and anti-apoptotic/inflammatory effects after Lpar1/Edg2 activation (Nam et al., 2020). Lpar1/ERK contributes to neuronal reorganization through Abeta $(\mathrm{A} \beta)$ fibers, and leads to neuropathic allodynia (Xie et al., 2008). Neuronal damage is significantly reduced in hyperbaric oxygen ( $\mathrm{HBO}$ )-treated rats compared with control rats after hypoxic-ischemic brain injury, and Lpar1/Edg2 plays a neuroprotective role in the brains of HBO-treated rats (Hirata et al., 2007). Enhanced LPA-Lpar1 signaling has been shown to inhibit programmed cell death and enhance neurogenesis through premature cell cycle exit and neuronal differentiation (Kingsbury et al., 2003).

Lysophosphatidic acid receptor 1/Endothelial differentiation gene-2 receptor is also found in developing neurons (neuroblasts) and enhances the differentiation of neocortical neuroblasts into mature neurons. Kim et al. (2019) reported that the E-protein
HeLa E-box binding protein (HEB) (encoded by the Tcf12 gene) represses Lpar1/Edg2 promoter activity by binding to the third E-box (EB3) in mouse neocortical neuroblasts and plays an important role in brain development (Figure 5).

\section{Edg2 in Astrocytes}

Astrocytes account for approximately $20-40 \%$ of all glial cells in the CNS (Ji et al., 2019). Astrocytes originate from NPCs and are classified into two types: type 1 astrocytes (protoplasmic astrocytes, localized in the gray matter) and type 2 astrocytes (fibrous astrocytes, localized in the white matter) (Domingues et al., 2016). Astrocytes provide structural and nutrient support for neurons and play an important role in many critical neural processes, such as by contacting inter-neuronal synapses, regulating neuroinflammation, and thus mediating CNS diseases, including gliomas and neuropsychiatric, neurodegenerative and neurodevelopmental diseases (Tabuchi et al., 2000). Astrocytes are quiescent in normal resting CNS tissue. However, astrocytes become activated by many mechanisms upon injury, resulting in mild astrogliosis (Domingues et al., 2016).

Lysophosphatidic acid receptor 1/Endothelial differentiation gene- 2 receptor enhances astrocytes proliferation. Lpar1/Edg2 is highly expressed in astrocytes (Tabuchi et al., 2000; Nakajima et al., 2018). LPA-Lpar1 has mitogenic activity in astrocytes. LPA stimulates DNA synthesis in rat astrocytes (Tabuchi et al., 2000). Lpar1/Edg2 contributes to 2-O-carba-cyclic phosphatidic acid (2ccPA)-induced DNA synthesis in astrocytes through the activation of the ERK pathway (Nakajima et al., 2018). LPALpar1 exerts mitogenic activity in astrocytes and induces the expression of several genes, including nerve growth factor (NGF) (Tabuchi et al., 2000).

Lysophosphatidic acid receptor 1/Endothelial differentiation gene- 2 receptor can also regulate astrocyte morphology and thus influence synaptic transmission and plasticity (Tabuchi et al., 2000). LPA has a dramatic effect on astrocyte morphology, potentially altering the volume of the synaptic cleft, and

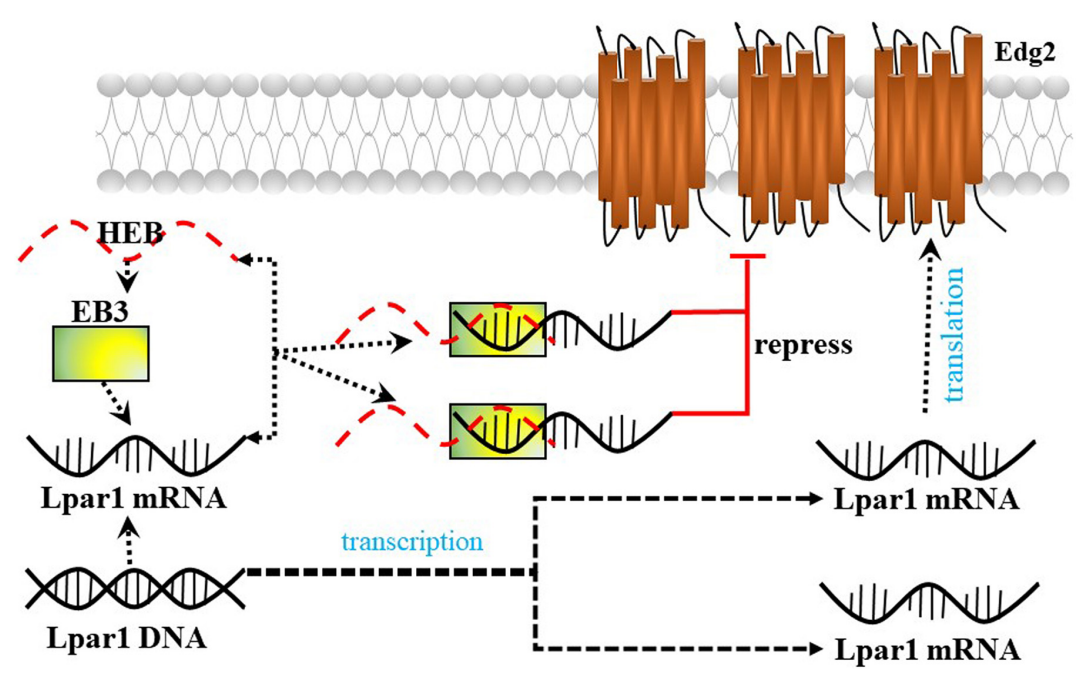

FIGURE $\mathbf{5}$ | The possible mechanism by which HEB repress Lpar1. 
TABLE 1 | The role of Lpar1 in the CNS.

\begin{tabular}{|c|c|c|c|c|}
\hline Cell type & Disease model & Function & Mechanism & References \\
\hline \multirow[t]{2}{*}{ NSCs } & $\begin{array}{l}\text { Neurological and } \\
\text { psychiatric } \\
\text { diseases }\end{array}$ & $\begin{array}{c}\text { Progenitor differentiation into intermediate } \\
\text { progenitor cells }\end{array}$ & Cell division & $\begin{array}{l}\text { McDonald } \\
\text { et al., } 2020\end{array}$ \\
\hline & NA & $\begin{array}{l}\text { LPA-Lpar1 signaling enhance neurogenesis and } \\
\text { decrease programmed cell death }\end{array}$ & $\begin{array}{l}\text { Cells averting programmed cell death, through } \\
\text { premature cell cycle exit and neuronal differentiation }\end{array}$ & $\begin{array}{l}\text { Kingsbury } \\
\text { et al., 2003; } \\
\text { McDonald } \\
\text { et al., } 2020\end{array}$ \\
\hline Oligodendrocytes & NA & Oligodendrocytes morphology & $\begin{array}{l}\text { Cytoskeletal rearrangements, which are involved in } \\
\text { oligodendrocytes outgrowth to membrane sheath } \\
\text { formation }\end{array}$ & $\begin{array}{l}\text { Nogaroli } \\
\text { et al., } 2009\end{array}$ \\
\hline \multirow[t]{2}{*}{ OPCs } & $\begin{array}{l}\text { A model precursor } \\
\text { OL line }\end{array}$ & Cell migration & LPA/Lpar1/Rho-ROCK & $\begin{array}{l}\text { Dawson } \\
\text { et al., } 2003\end{array}$ \\
\hline & $\begin{array}{l}\text { Immortalized } \\
\text { oligodendrocyte } \\
\text { cell line (OLP6) }\end{array}$ & $\begin{array}{l}\text { Anti-apoptosis and promote OPCs } \\
\text { differentiation }\end{array}$ & $\begin{array}{l}\text { Lpar1/Gi/o/MAPK; Lpar1/Gi/o/adenylyl cyclase } \\
\text { inhibition }\end{array}$ & $\begin{array}{l}\text { Matsushita } \\
\text { et al., } 2005\end{array}$ \\
\hline \multirow[t]{2}{*}{ Pre-OLs } & NA & Latest stages of oligodendrocyte maturation & ERK1/ERK2 & $\begin{array}{l}\text { Stankoff } \\
\text { et al., } 2002\end{array}$ \\
\hline & NA & Latest stages of oligodendrocyte maturation & & $\begin{array}{l}\text { Nogaroli } \\
\text { et al., } 2009\end{array}$ \\
\hline \multirow[t]{5}{*}{ Mature OLs } & $\begin{array}{l}\text { Demyelinating } \\
\text { diseases }\end{array}$ & Trafficking of PLP & $\begin{array}{l}\text { Vesicle-mediated endocytosis and recycling to the } \\
\text { plasma membrane disrupt }\end{array}$ & $\begin{array}{l}\text { Garcia-Diaz } \\
\text { et al., } 2015\end{array}$ \\
\hline & I & Stress-induced OLs apoptosis & & $\begin{array}{l}\text { Garcia-Diaz } \\
\text { et al., } 2015\end{array}$ \\
\hline & & Enhance oligodendrocytes differentiation and my & nation & \\
\hline & $\begin{array}{l}\text { HIV infected } \\
\text { patients WMI }\end{array}$ & / & ATX-LPA signaling & $\begin{array}{l}\text { Wheeler } \\
\text { et al., } 2016\end{array}$ \\
\hline & $\begin{array}{l}\text { Ischemic } \\
\text { reperfusion injury }\end{array}$ & Anti-apoptosis & / & $\begin{array}{l}\text { Savitz et al., } \\
2006\end{array}$ \\
\hline \multirow[t]{5}{*}{ Astrocytes } & $\begin{array}{l}\text { Traumatic brain } \\
\text { injury }\end{array}$ & Reactive astrocytes & / & \\
\hline & Depression & Astrocytes DNA synthesis & Lpar1/ERK & $\begin{array}{l}\text { Nakajima } \\
\text { et al., } 2018\end{array}$ \\
\hline & Depression & Astrocytes DNA synthesis & Lpar1/Gi/o/Src family tyrosine kinase/MMP-9 & $\begin{array}{l}\text { Abe et al., } \\
2019\end{array}$ \\
\hline & $\begin{array}{l}\text { Astrocytic shape } \\
\text { changes }\end{array}$ & Mitogenic activity & LPA/Lpar1/NGF & $\begin{array}{l}\text { Tabuchi et al., } \\
2000\end{array}$ \\
\hline & & Astrocytes DNA synthesis & ERK1/2/GDNF & $\begin{array}{l}\text { Kajitani et al., } \\
2016\end{array}$ \\
\hline \multirow[t]{9}{*}{ Neuron } & $\begin{array}{l}\text { Neuroblastoma } \\
\text { cells }\end{array}$ & Cell migration & Lpar1/Gi/o/Mmp-2 & $\begin{array}{l}\text { Kato et al., } \\
2012\end{array}$ \\
\hline & $\begin{array}{l}\text { Neuropathic } \\
\text { allodynia }\end{array}$ & $\begin{array}{l}\text { Neuronal reorganization through Abeta } \\
\qquad(\mathrm{A} \beta) \text {-fibber }\end{array}$ & Lpar1/ERK & $\begin{array}{l}\text { Xie et al., } \\
2008\end{array}$ \\
\hline & $\begin{array}{l}\text { Hippocampal } \\
\text { neurons }\end{array}$ & $\begin{array}{l}\text { Decrease programmed cell death and enhance } \\
\text { neurogenesis }\end{array}$ & Premature cell cycle exit and neuronal differentiation & $\begin{array}{l}\text { Kingsbury } \\
\text { et al., } 2003\end{array}$ \\
\hline & & Increase neuronal excitability & $\begin{array}{l}\text { PLC-dependent signaling pathway and } \\
\text { voltage-gated potassium (Kv) channel/Lpar1/Ca2 }{ }^{+} \\
\text {current }\end{array}$ & $\begin{array}{l}\text { Park et al., } \\
2015\end{array}$ \\
\hline & Neuroblast cells & Represses Lpar1 promoter activity & HEB binding to EB3 inhibit Lpar1 promoter & $\begin{array}{l}\text { Kim et al., } \\
2019\end{array}$ \\
\hline & $\begin{array}{l}\text { Neuroblastoma } \\
\text { cells }\end{array}$ & Cell motility & Lpar1 coupled to Gi, Gq, G12/13, and ROCK & $\begin{array}{l}\text { Hayashi } \\
\text { et al., } 2012\end{array}$ \\
\hline & $\begin{array}{l}\text { Neuropathic pain } \\
\text { mice }\end{array}$ & / & $\begin{array}{l}\text { Lpar1/Edg2 mediated amplification of spinal LPA } \\
\text { production }\end{array}$ & $\begin{array}{l}\text { Uchida et al., } \\
2014\end{array}$ \\
\hline & Neuropathic pain & Development of allodynia and hyperalgesia & LPA/Lpar1/Rho-ROCK & $\begin{array}{l}\text { Inoue et al., } \\
2004\end{array}$ \\
\hline & Neuropathic pain & $\begin{array}{l}\text { Upregulation of Lpar1/Edg2 and Nav1.8 in } \\
\text { DRGs of normal rats }\end{array}$ & LPA/Lpar1/G protein/MAPK/PKC/Rho & $\begin{array}{l}\text { Pan et al., } \\
2016\end{array}$ \\
\hline
\end{tabular}


TABLE 1 | Continued

\begin{tabular}{|c|c|c|c|c|}
\hline Cell type & Disease model & Function & Mechanism & References \\
\hline & $\begin{array}{l}\text { Alzheimer's disease } \\
\text { (AD) }\end{array}$ & $\begin{array}{l}\text { Circ-Lpar1 might regulate neuronal cell death and } \\
\text { neuroinflammation by sponging their target miRNAs }\end{array}$ & / & Li et al., 2020 \\
\hline \multirow[t]{6}{*}{ Microglia } & & Microglia migration & Rho and ERK1/2 & $\begin{array}{l}\text { Bernhart et al., } \\
2010\end{array}$ \\
\hline & Neuropathic pain & Microglia activation & $\begin{array}{l}\text { Lpar1/microglia activation, ATP release and } \\
\text { BDNF upregulation }\end{array}$ & Fujita et al., 2008 \\
\hline & & $\begin{array}{l}\text { LPA activated pro-inflammatory process and triggers M1 } \\
\qquad \text { polarization }\end{array}$ & LPA/Lpar1 & $\begin{array}{l}\text { Fransson et al., } \\
2020\end{array}$ \\
\hline & & Alleviate demyelination and microglia polarization & Lpar1/MAPK/Keap1/Nrf2 & Choi et al., 2020 \\
\hline & & Neurotoxic microglia polarization & Lpar1/MAPK & Plastira et al., 2020 \\
\hline & & Activating microglia induced demyelination & LPA/Lpar1 & $\begin{array}{l}\text { Santos-Nogueira } \\
\text { et al., } 2015\end{array}$ \\
\hline
\end{tabular}

thus modulate neurotransmitter concentrations and interactions between neurons and glia. Tabuchi et al. (2000) found that LPALpar1 induces $\mathrm{Ca}^{2+}$ mobilization in rat primary astrocytes, which indicates that LPA may also serve as a neuromodulator.

In addition, Lpar1/Edg2 can regulate the secretion of neurotrophic factor genes by astrocytes. LPA-Lpar1 signaling increases glial cell line-derived neurotrophic factor (GDNF) mRNA expression in astrocytes. GDNF is a neurotrophic/growth factor that supports neurogenesis, gliogenesis, neural plasticity and cell survival in the brain (Abe et al., 2019). GDNF expression has been found to be decreased in patients with major depression (Abe et al., 2019), and antidepressant treatment can significantly increase GDNF levels in patients with major depression (Abe et al., 2019). Fibroblast growth factor receptor (FGFR), FGFR substrate $2 \alpha$ (FRS2 $\alpha$ ) and ERK1/2 are related to GDNF expression through the Lpar1-mediated signaling pathway (Kajitani et al., 2016). Gi/o-coupled Lpar1-induced phosphorylation of ERK1/2 in astrocytes mediates GDNF mRNA expression (Kajitani et al., 2016). The antidepressant amitriptyline increases GDNF production via the Gi/o-coupled Lpar1/matrix metalloproteinase-9 (MMP-9)/FGFR/ERK cascade. Recent findings indicate that amitriptyline activates a Lpar1/Gi/o/Src family tyrosine kinase/MMP-9 cascade in astroglial cells (Abe et al., 2019).

LPA-Lpar1 promotes astrocytes to transcribe various genes and secrete a variety of cytokines, such as immediate-early genes ( $c$-fos and $c$-jun, which promote cell proliferation and differentiation), NGF, IL-1, IL-3, and IL-6, the levels of which are increased when astrocytes are activated or proliferate (Tabuchi et al., 2000).

\section{Edg2 in Microglia}

Microglia, which arise from hematopoietic stem cells in the yolk sac during early embryogenesis, account for approximately $10 \%$ of all glial cells in the CNS (Domingues et al., 2016). Microglia can be classified into two groups according to phenotype: M1 microglia (pro-inflammatory and neurotoxic) and M2 microglia (anti-inflammatory microglia involved in neural repair) (Yu et al., 2020). Steady-state microglia might promote oligodendrocyte differentiation by providing trophic support to OPCs. However, LPS-mediated inflammation polarizes microglia, thus preventing oligodendrocyte differentiation (Domingues et al., 2016). Microglia promote apoptosis of differentiated cells via mechanisms including tumor necrosis factor (TNF) signaling, NGF secretion, and reactive oxygen species (ROS) production (Thion et al., 2018). Microglia participate in the establishment of neuronal connections by promoting outgrowth or fasciculation of axonal tracts during pre- and post-natal development. Microglia can also influence neuronal migratory processes. Additionally, microglia are involved in promoting the formation of excitatory synapses (Bartels et al., 2020).

Lysophosphatidic acid receptor 1/Endothelial differentiation gene- 2 receptor has been found to be expressed in mouse and rat microglia and to be related to $\mathrm{Ca}^{2+}$ influx (Möller et al., 2001). LPA-Lpar1 might activate microglia in response to CNS injury (Möller et al., 2001). Human immortalized C13NJ microglia express Lpar1 (Bernhart et al., 2010). Lpar1/Edg2 activation leads to the activation of Rho and ERKs, which triggers an increase in ATP production, alters the actin and tubulin cytoskeleton, and decreases cell migration (Bernhart et al., 2010). Neuroinflammation is critical during neurodegeneration. LPA-Lpar1 signaling can induce microglial polarization toward a protective or neurotoxic phenotype by activating MAPK (Plastira et al., 2020). Santos-Nogueira et al. (2015) found that LPA levels are increased in the mouse spinal cord after contusion injury. Exogenous LPA injection was shown to activate microglia and induce demyelination secondary to axon or myelin damage. Microglial Lpar1 is responsible for exogenous LPA-induced demyelination. These findings indicate that LPA leads to demyelination by activating microglia Lpar1 (Santos-Nogueira et al., 2015).

\section{THE ROLES OF Lpar1 IN CNS DISORDERS AND DISEASES}

\section{Brain Tumors}

Matrix metalloproteinases (MMPs) are involved in extracellular matrix degradation and associated with tumor invasion and metastasis. Mutated Lpar1 stimulates the expression and activity of MMP-2 in rat neuroblastoma cells (Kato et al., 2012). It has 
been reported that mutated Lpar1 increases cell motility and invasion of rat neuroblastoma cells (Hayashi et al., 2012). These results suggest that Lpar1/Edg2 might inhibit the motility and invasion of neuroblastoma cells. Hirane et al. (2013) reported that Lpar1 markedly suppresses B103 cell motility stimulated by hydrogen peroxide and 2,3-dimethoxy-1,4-naphthoquinone (DMNQ). It has been found that Lpar1/Edg2 plays different roles in cell proliferation and the migration of rat neuroblastoma cells (Hayashi et al., 2012). Lpar1/Edg2 couples to Gi, Gq, G12/13, and ROCK to affect cell motility (Hayashi et al., 2012). Lpar1/Edg2 receptor couples to $\mathrm{G} \alpha 12 / 13$ to mediate RhoGEF/RhoA-GTP and thus affect actomyosin contraction and couples to Gi to mediate PI3K $\beta /$ Tiam $1 /$ Rac-GTP and therefore affect cell spreading and lamellipodia formation, thus altering the migration and motility of B103 neuroblastoma cells (Van Leeuwen et al., 2003; Figure 3). Loss of primary cilia has been shown to affect cell proliferation in glioblastoma. Lpar1/Edg2 accumulates in primary cilia and has been reported to be responsible for the proliferation of glioblastoma patient-derived cells through coupling to $\mathrm{G} \alpha 12 / \mathrm{G} \alpha \mathrm{q}$ (Loskutov et al., 2018).

\section{Multiple Sclerosis (MS) and Experimental Autoimmune Encephalomyelitis (EAE)}

The pathogeneses of $\mathrm{MS}$ and EAE involve inflammation in the CNS (microglial polarization) and demyelination (oligodendrocyte death and myelin damage). During remyelination, M1 (pro-inflammatory) macrophages phagocytize myelin debris and induce OPCs to proliferate and migrate to the lesion site. Next, a switch from M1 (pro-inflammatory) to M2 (anti-inflammatory) phenotype induces the secretion of trophic factors that promotes the differentiation of OPCs into new mature and myelinating oligodendrocytes (Fransson et al., 2020). Fransson et al. (2020) analyzed Lpar1/Edg2 expression levels in peripheral blood mononuclear cells (PBMCs) from EAE mice and patients with relapsing MS and found increased Lpar1/Edg2 expression in these cells. The levels of different M1 markers, such as CCL2, CCL20, CCL5, and TLR2, were shown to be increased after incubation with LPA, and M1 polarization was shown to be partially suppressed by the addition of an Lpar1/Edg2 inhibitor (Ki16425). Collectively, these results indicate that LPA activates a pro-inflammatory response and triggers M1 polarization through Lpar1/Edg2 (Fransson et al., 2020). Gintonin, a ginseng-derived exogenous LPA ligand, may alleviate demyelination and microglial polarization in EAE by enhancing anti-inflammatory and antioxidant activities through stimulating the Lpar1/MAPK and Kelch-like ECH associated protein 1 (Keap1)-nuclear factor erythroid 2-related factor 2 (Nrf2) pathways (Choi et al., 2020).

\section{White Matter Injury (WMI)}

The most common type of brain injury in premature neonates is diffuse WMI, which involves oligodendrocyte maturation arrest and hypomyelination, resulting in cognitive, behavioral, and sensory disabilities as well as psychological disorders later in life (van Tilborg et al., 2016). Garcia-Diaz et al. (2015) found that loss of Lpar1 suppresses oligodendrocyte differentiation and myelination, suggesting that Lpar1 plays an important role in WMI. WMI has been frequently reported in HIVinfected patients. It has been reported that ATX-LPA signaling participates in oligodendrocyte differentiation in HIV-infected patients (Wheeler et al., 2016). Collectively, we speculate that Lpar1/Edg2 may promote oligodendrocyte differentiation and protect against WMI.

\section{Ischemia-Reperfusion Injury}

Lysophosphatidic acid receptor 1/Endothelial differentiation gene- 2 receptor expression is upregulated in the vulnerable inner retinal layers secondary to ischemia-reperfusion injury. Hirata et al. (2007) analyzed the expression of genes and confirmed the results by evaluating protein expression to determine the neuroprotective mechanism of $\mathrm{HBO}$, and the researchers found that Lpar1/Edg2 expression is significantly upregulated by HBO treatment. Upregulation of Lpar1/Edg2 expression plays an important neuroprotective role upon $\mathrm{HBO}$ treatment after ischemic brain injury (Hirata et al., 2007). Lpar1/Edg2 can prevent apoptosis of numerous neuronal cell types and glial cells after ischemia-reperfusion injury (Savitz et al., 2006).

\section{Neuropathic Pain}

Lysophosphatidic acid receptor 1/Endothelial differentiation gene- 2 receptor is expressed in both DRG neurons and the dorsal root (Nagai et al., 2010). Uchida et al. (2014) found that Lpar1/Edg2-mediated amplification of spinal LPA production is required for the induction of neuropathic pain after nerve injury. LPA-Lpar1 and Rho-ROCK activation was shown to be crucial for the development of allodynia and hyperalgesia in a model of neuropathic pain (Inoue et al., 2004). LPAinduced upregulation of Lpar1/Edg2 and Nav1.8 expression in the DRGs of normal rats results in pain behavior in bone cancer (Pan et al., 2016). LPA is important for the initiation of neuropathic pain via the coupling of Lpar1/Edg2 to G proteins and downstream propagation of Lpar1/Edg2 signals through the MAPK, protein kinase $\mathrm{C}$ (PKC), and Rho pathways (Pan et al., 2016). Lpar1/Edg2-mediated microglial activation, ATP release and $\mathrm{BDNF}$ expression upregulation may contribute to the maintenance of neuropathic pain (Fujita et al., 2008).

\section{Psychiatric Disorders}

The Lpar1/Edg2 level in the whole peripheral blood of patients with major depression is related to mood (Kéri et al., 2014). Lpar1/Edg2 is also one of the ten top blood candidate biomarker genes for mood (Le-Niculescu et al., 2009). Lpar1/Edg2 expression is downregulated in the temporal cortices of subjects with major depressive disorder compared with those of control participants (Aston et al., 2005) and in the peripheral blood lymphocytes of schizophrenia patients compared with those of control participants (Bowden et al., 2006). The maLpar1null mouse model exhibits depressive and anxious behaviors, which implies that researchers should develop drugs targeting Lpar1/Edg2 receptor as treatments for depression, mainly the anxious subtype (Moreno-Fernández et al., 2018).

Psychiatric disorders including schizophrenia, affect public health and are thought to have an etiology. The association 
between Lpar1 and schizophrenia was reported by some studies (Harrison et al., 2003; Roberts et al., 2005). They reported that a marked deficit in prepulse inhibition and alteration of neurotransmitter in Lpar1 $\left({ }^{-} /^{-}\right)$mice compared with wild type. Roberts et al. (2005) reported that Lpar1 mutation produces a number of changes in neurotransmitters, including 5-hydroxytryptamine (5-HT), tyrosine, aspartate, glutamate and $\gamma$-aminobutyric acid (GABA), that have been associated with a schizophrenia-like pathology in mice model. They found that a significant decrease of 5-HT and GABA, while a significant increase of tyrosine, aspartate and glutamate was observed in Lpar1 $\left({ }^{-} /^{-}\right)$mice compared with Lpar1 $\left(^{+} / /^{+}\right)$mice (Roberts et al., 2005).

\section{Other Diseases}

Lysophosphatidic acid receptor 1/Endothelial differentiation gene- 2 receptor, which is expressed on fibers and is present on reactive astrocytes in the corpus callosum, specifically affects axonal damage following traumatic brain injury (TBI) (Frugier et al., 2011). Circ-Lpar1 expression is upregulated in Alzheimer's disease $(\mathrm{AD})$ patients compared with control participants ( $\mathrm{Li}$ et al., 2020). Circ-Lpar1 levels can predict the risk of AD with an OR of 2.984 (95\% CI, 1.644-5.416). Circ-Lpar1 might regulate neuronal cell death and neuroinflammation by sponging its target miRNAs, thus elevating the risk for AD. The effects of gintonin against Parkinson's disease are mediated via Lpar1 (Choi et al., 2018), and the Lpar1/Edg2 was downregulated in Parkinson's disease rat model (Yang et al., 2015). It demonstrated that low expression of Edg2 in Parkinson's disease rat model may result in neuron loss, which contributed to the pathology of Parkinson's disease. Gintonin can activate Keap1-Nrf2 signaling through the LPA-Lpar1 signaling pathway to treat Huntington's disease (HD) (Jang et al., 2019). Lpar1/Edg2 is also differentially expressed in the post-mortem brains of cocaine abusers compared to those of control participants (Kristiansen et al., 2009). Additionally, Lpar1 is required for normal development of neonatal behavior. Lpar1 deletion results in impaired suckling in neonatal pups, and the sucking defect may responsible for Lpar1 deletion induced death (Contos J.J.A. et al., 2000), and Lummis et al. (2019) reported that Lpar1 was identified as a key mediator of posthemorrhagic hydrocephalus $(\mathrm{PHH})$ in premature animal model.

\section{CONCLUSION AND FUTURE PERSPECTIVES}

Collectively, these findings suggest that Lpar1 is essential for maintaining the normal functions of the CNS. Any alteration

\section{REFERENCES}

Abe, H., Kajitani, N., Okada-Tsuchioka, M., Omori, W., Yatsumoto, M., and Takebayashi, M. (2019). Antidepressant amitriptyline-induced matrix metalloproteinase- 9 activation is mediated by SRC family tyrosine kinase, which leads to glial cell line-derived neurotrophic factor mRNA expression in rat astroglial cells. Neuropsychopharmacol. Rep. 39, 156-163. doi: 10.1002/npr2. 12055 in Lpar1 function or expression may lead to CNS disorders or diseases. The upstream molecules that regulate Lpar1 in the CNS need to be further studied.

MicroRNAs are short nucleotides that can bind to target mRNAs and then inhibit their translation into proteins. Binding of miR-892b to Lpar1 mRNA can downregulate Edg2 expression. LncRNAs, as competing RNAs (ceRNAs), can bind to microRNAs to inhibit microRNA function, especially by upregulating target protein expression. It has been reported that lncRNA ZFAS1 enhances tumorigenesis and metastasis in nasopharyngeal carcinoma by upregulating Edg2 expression in a miR-892b-dependent manner (Peng et al., 2020). Additionally, the genes that bind to the promotor of Lpar1, such as HEB, might regulate its expression and affect its function. Future studies will further determine whether these upstream molecules regulate Lpar1, especially in the context of demyelinating diseases and postnatal WMI.

A recent study revealed that Lpar1/Edg2 expression is increased in PBMCs from EAE mice and patients with relapsing MS; additionally, circ-Lpar1 expression in upregulated in AD patients compared with control participants. These studies indicate that Lpar1/Edg2 may aid in diagnosis in the near future and be a therapeutic target.

\section{AUTHOR CONTRIBUTIONS}

DX, XL, and YQ: conceptualization. DX, XS, HG, XL, and YQ: software, validation, investigation, resources, and writingreview and editing. DX: writing-original draft preparation. $\mathrm{XL}$ and YQ: visualization and supervision. DX, HG, XL, and YQ: funding acquisition. All authors read and approved the final manuscript.

\section{FUNDING}

This work was supported by the National Natural Science Foundation of China (82001593, 81971433, 82071353, 81771634, and 81971428) and Key R\&D Projects of Science and Technology Department of Sichuan Province (2021YFS0029 and 2020YFS0104).

\section{ACKNOWLEDGMENTS}

This manuscript was edited by American Journal Experts (AJE) with certification number (HRJ8GYW6).

Allard, J., Barrón, S., Diaz, J., Lubetzki, C., Zalc, B., Schwartz, J. C., et al. (1998). A rat G protein-coupled receptor selectively expressed in myelinforming cells. Eur. J. Neurosci. 10, 1045-1053. doi: 10.1046/j.1460-9568.1998.0 0117.x

Allard, J., Barron, S., Trottier, S., Cervera, P., Daumas-Duport, C., Leguern, E., et al. (1999). Edg-2 in myelin-forming cells: isoforms, genomic mapping, and exclusion in Charcot-Marie-Tooth disease. Glia 26, 176-185. doi: 10.1002/(sici) 1098-1136(199904)26:2<176::aid-glia8>3.0.co;2-k 
An, S., Dickens, M. A., Bleu, T., Hallmark, O. G., and Goetzl, E. J. (1997). Molecular cloning of the human Edg2 protein and its identification as a functional cellular receptor for lysophosphatidic acid. Biochem. Biophys. Res. Commun. 231, 619-622. doi: 10.1006/bbrc.1997.6150

Aston, C., Jiang, L., and Sokolov, B. P. (2005). Transcriptional profiling reveals evidence for signaling and oligodendroglial abnormalities in the temporal cortex from patients with major depressive disorder. Mol. Psychiatry 10, 309322. doi: $10.1038 /$ sj.mp.4001565

Bartels, T., De Schepper, S., and Hong, S. (2020). Microglia modulate neurodegeneration in Alzheimer's and Parkinson's diseases. Science 370, 66-69. doi: 10.1126/science.abb8587

Bauer, J., Bradl, M., Klein, M., Leisser, M., Deckwerth, T. L., Wekerle, H., et al. (2002). Endoplasmic reticulum stress in PLP-overexpressing transgenic rats: gray matter oligodendrocytes are more vulnerable than white matter oligodendrocytes. J. Neuropathol. Exp. Neurol. 61, 12-22. doi: 10.1093/jnen/ 61.1.12

Bernhart, E., Kollroser, M., Rechberger, G., Reicher, H., Heinemann, A., Schratl, P., et al. (2010). Lysophosphatidic acid receptor activation affects the C13NJ microglia cell line proteome leading to alterations in glycolysis, motility, and cytoskeletal architecture. Proteomics 10, 141-158. doi: 10.1002/pmic. 200900195

Bowden, N. A., Weidenhofer, J., Scott, R. J., Schall, U., Todd, J., Michie, P. T., et al. (2006). Preliminary investigation of gene expression profiles in peripheral blood lymphocytes in schizophrenia. Schizophr. Res. 82, 175-183. doi: 10.1016/ j.schres.2005.11.012

Bradl, M., and Lassmann, H. (2010). Oligodendrocytes: biology and pathology. Acta Neuropathol. 119, 37-53. doi: 10.1007/s00401-009-0601-5

Choi, J. H., Jang, M., Oh, S., Nah, S. Y., and Cho, I. H. (2018). Multi-target protective effects of gintonin in 1-Methyl-4-phenyl-1,2,3,6-tetrahydropyridinemediated model of Parkinson's disease via lysophosphatidic acid receptors. Front. Pharmacol. 9:515. doi: 10.3389/fphar.2018.00515

Choi, J. H., Oh, J., Lee, M. J., Ko, S. G., Nah, S. Y., and Cho, I. H. (2020). Gintonin mitigates experimental autoimmune encephalomyelitis by stabilization of Nrf2 signaling via stimulation of lysophosphatidic acid receptors. Brain Behav. Immun. 93, 384-398. doi: 10.1016/j.bbi.2020.12.004

Choi, J. W., Herr, D. R., Noguchi, K., Yung, Y. C., Lee, C. W., Mutoh, T., et al. (2010). LPA receptors: subtypes and biological actions. Annu. Rev. Pharmacol. Toxicol. 50, 157-186. doi: 10.1146/annurev.pharmtox.010909.1 05753

Contos, J. J., Ishii, I., and Chun, J. (2000). Lysophosphatidic acid receptors. Mol. Pharmacol. 58, 1188-1196.

Contos, J. J. A., Fukushima, N., Weiner, J. A., Kaushal, D., and Chun, J. (2000). Requirement for the Ip(A1) lysophosphatidic acid receptor gene in normal suckling behavior. Proc. Natl. Acad. Sci. U.S.A. 97, 13384-13389. doi: 10.1073/ pnas.97.24.13384

Czepiel, M., Boddeke, E., and Copray, S. (2015). Human oligodendrocytes in remyelination research. Glia 63, 513-530. doi: 10.1002/glia.22769

Dawson, J., Hotchin, N., Lax, S., and Rumsby, M. (2003). Lysophosphatidic acid induces process retraction in CG-4 line oligodendrocytes and oligodendrocyte precursor cells but not in differentiated oligodendrocytes. J. Neurochem. 87, 947-957. doi: 10.1046/j.1471-4159.2003.02056.x

de San Roman, E. G., Manuel, I., Teresa Giralt, M., Chun, J., Estivill-Torrus, G., Rodriguez de Fonseca, F., et al. (2015). Anatomical location of LPA(1) activation and LPA phospholipid precursors in rodent and human brain. J. Neurochem. 134, 471-485. doi: 10.1111/jnc. 13112

Domingues, H. S., Portugal, C. C., Socodato, R., and Relvas, J. B. (2016). Oligodendrocyte, astrocyte, and microglia crosstalk in myelin development, damage, and repair. Front. Cell Dev. Biol. 4:71. doi: 10.3389/fcell.2016.00071

Erickson, J. R., Wu, J. J., Goddard, J. G., Tigyi, G., Kawanishi, K., Tomei, L. D., et al. (1998). Edg-2/Vzg-1 couples to the yeast pheromone response pathway selectively in response to lysophosphatidic acid. J. Biol. Chem. 273, 1506-1510. doi: 10.1074/jbc.273.3.1506

Feldmann, A., Amphornrat, J., Schönherr, M., Winterstein, C., Möbius, W., Ruhwedel, T., et al. (2011). Transport of the major myelin proteolipid protein is directed by VAMP3 and VAMP7. J. Neurosci. 31, 5659-5672. doi: 10.1523/ jneurosci.6638-10.2011
Fransson, J., ómez-Conde, A. I. G., Romero-Imbroda, J., Fernández, O., Leyva, L., de Fonseca, F. R., et al. (2020). Activation of macrophages by lysophosphatidic acid through the lysophosphatidic acid receptor 1 as a novel mechanism in multiple sclerosis pathogenesis. Mol. Neurobiol. 58, 470-482. doi: 10.1007/ s12035-020-02130-x

Frugier, T., Crombie, D., Conquest, A., Tjhong, F., Taylor, C., Kulkarni, T., et al. (2011). Modulation of LPA receptor expression in the human brain following neurotrauma. Cell. Mol. Neurobiol. 31, 569-577. doi: 10.1007/s10571-0119650-0

Fujita, R., Ma, Y., and Ueda, H. (2008). Lysophosphatidic acid-induced membrane ruffling and brain-derived neurotrophic factor gene expression are mediated by ATP release in primary microglia. J. Neurochem. 107, 152-160. doi: 10.1111/j. 1471-4159.2008.05599.x

Garcia-Diaz, B., Riquelme, R., Varela-Nieto, I., Jesus Jimenez, A., de Diego, I., lsabel Gomez-Conde, A., et al. (2015). Loss of lysophosphatidic acid receptor LPA(1) alters oligodendrocyte differentiation and myelination in the mouse cerebral cortex. Brain Struct. Funct. 220, 3701-3720. doi: 10.1007/s00429-014-0885-7

Goldman, S. A., and Kuypers, N. J. (2015). How to make an oligodendrocyte. Development 142, 3983-3995. doi: 10.1242/dev.126409

Handford, E. J., Smith, D., Hewson, L., McAllister, G., and Beer, M. S. (2001). Edg2 receptor distribution in adult rat brain. Neuroreport 12, 757-760. doi: 10.1097/00001756-200103260-00029

Harrison, S. M., Reavill, C., Brown, G., Brown, J. T., Cluderay, J. E., Crook, B., et al. (2003). LPA(1) receptor-deficient mice have phenotypic changes observed in psychiatric disease. Mol. Cell. Neurosci. 24, 1170-1179. doi: 10.1016/j.mcn. 2003.09.001

Hayashi, M., Okabe, K., Kato, K., Okumura, M., Fukui, R., Fukushima, N., et al. (2012). Differential function of lysophosphatidic acid receptors in cell proliferation and migration of neuroblastoma cells. Cancer Lett. 316, 91-96. doi: 10.1016/j.canlet.2011.10.030

Hecht, J. H., Weiner, J. A., Post, S. R., and Chun, J. (1996). Ventricular zone gene1 (vzg-1) encodes a lysophosphatidic acid receptor expressed in neurogenic regions of the developing cerebral cortex. J. Cell Biol. 135, 1071-1083. doi: 10.1083/jcb.135.4.1071

Hirane, M., Araki, M., Dong, Y., Honoki, K., Fukushima, N., and Tsujiuchi, T. (2013). Inhibitory effects of LPA1 on cell motile activities stimulated by hydrogen peroxide and 2,3-dimethoxy-1,4-naphthoquinone in fibroblast 3T3 cells. Biochem. Biophys. Res. Commun. 441, 47-52. doi: 10.1016/j.bbrc.2013.10. 009

Hirata, T., Cui, Y. J., Funakoshi, T., Mizukami, Y., Ishikawa, Y., Shibasaki, F., et al. (2007). The temporal profile of genomic responses and protein synthesis in ischemic tolerance of the rat brain induced by repeated hyperbaric oxygen. Brain Res. 1130, 214-222. doi: 10.1016/j.brainres.2006.10.077

Hla, T., Jackson, A. Q., Appleby, S. B., and Maciag, T. (1995). Characterization of edg-2, a human homologue of the Xenopus maternal transcript G10 from endothelial cells. Biochim. Biophys. Acta 1260, 227-229. doi: 10.1016/01674781(94)00219-s

Inoue, M., Rashid, M. H., Fujita, R., Contos, J. J., Chun, J., and Ueda, H. (2004). Initiation of neuropathic pain requires lysophosphatidic acid receptor signaling. Nat. Med. 10, 712-718. doi: 10.1038/nm1060

Ishii, S., Tsujiuchi, T., and Fukushima, N. (2017). Functional characterization of lysophosphatidic acid receptor 1 mutants identified in rat cancer tissues. Biochem. Biophys. Res. Commun. 486, 767-773. doi: 10.1016/j.bbrc.2017.03.118

Jang, M., Choi, J. H., Chang, Y., Lee, S. J., Nah, S. Y., and Cho, I. H. (2019). Gintonin, a ginseng-derived ingredient, as a novel therapeutic strategy for Huntington's disease: activation of the Nrf2 pathway through lysophosphatidic acid receptors. Brain Behav. Immun. 80, 146-162. doi: 10.1016/j.bbi.2019.03. 001

Ji, R. R., Donnelly, C. R., and Nedergaard, M. (2019). Astrocytes in chronic pain and itch. Nat. Rev. Neurosci. 20, 667-685. doi: 10.1038/s41583-0190218-1

Kajitani, N., Miyano, K., Okada-Tsuchioka, M., Abe, H., Itagaki, K., HisaokaNakashima, K., et al. (2016). Identification of lysophosphatidic acid receptor 1 in astroglial cells as a target for glial cell line-derived neurotrophic factor expression induced by antidepressants. J. Biol. Chem. 291, 27364-27370. doi: $10.1074 /$ jbc.m116.753871 
Kato, K., Fukui, R., Okabe, K., Tanabe, E., Kitayoshi, M., Fukushima, N., et al. (2012). Constitutively active lysophosphatidic acid receptor-1 enhances the induction of matrix metalloproteinase-2. Biochem. Biophys. Res. Commun. 417, 790-793. doi: 10.1016/j.bbrc.2011.12.036

Kéri, S., Szabó, C., and Kelemen, O. (2014). Blood biomarkers of depression track clinical changes during cognitive-behavioral therapy. J. Affect Disord. 164, 118-122. doi: 10.1016/j.jad.2014.04.030

Kim, N. H., Sadra, A., Park, H. Y., Oh, S. M., Chun, J., Yoon, J. K., et al. (2019). HeLa E-Box binding protein, HEB, inhibits promoter activity of the lysophosphatidic acid receptor gene lpar1 in neocortical neuroblast cells. Mol. Cells 42, 123-134.

Kingsbury, M. A., Rehen, S. K., Contos, J. J., Higgins, C. M., and Chun, J. (2003). Non-proliferative effects of lysophosphatidic acid enhance cortical growth and folding. Nat. Neurosci. 6, 1292-1299. doi: 10.1038/nn1157

Kristiansen, L. V., Bannon, M. J., and Meador-Woodruff, J. H. (2009). Expression of transcripts for myelin related genes in postmortem brain from cocaine abusers. Neurochem. Res. 34, 46-54. doi: 10.1007/s11064-008-9655-3

Le-Niculescu, H., Kurian, S. M., Yehyawi, N., Dike, C., Patel, S. D., Edenberg, H. J., et al. (2009). Identifying blood biomarkers for mood disorders using convergent functional genomics. Mol. Psychiatry 14, 156-174. doi: 10.1038/mp.2008.11

Li, Y., Fan, H., Sun, J., Ni, M., Zhang, L., Chen, C., et al. (2020). Circular RNA expression profile of Alzheimer's disease and its clinical significance as biomarkers for the disease risk and progression. Int. J. Biochem. Cell Biol. 123:105747. doi: 10.1016/j.biocel.2020.105747

Loskutov, Y. V., Griffin, C. L., Marinak, K. M., Bobko, A., Margaryan, N. V., Geldenhuys, W. J., et al. (2018). LPA signaling is regulated through the primary cilium: a novel target in glioblastoma. Oncogene 37, 1457-1471. doi: 10.1038/ s41388-017-0049-3

Lummis, N. C., Sanchez-Pavon, P., Kennedy, G., Frantz, A. J., Kihara, Y., Blaho, V. A., et al. (2019). LPA(1/3) overactivation induces neonatal posthemorrhagic hydrocephalus through ependymal loss and ciliary dysfunction. Sci. $A d v$. 5:eaax2011. doi: 10.1126/sciadv.aax2011

Matsushita, T., Amagai, Y., Soga, T., Terai, K., Obinata, M., and Hashimoto, S. (2005). A novel oligodendrocyte cell line OLP6 shows the successive stages of oligodendrocyte development: late progenitor, immature and mature stages. Neuroscience 136, 115-121. doi: 10.1016/j.neuroscience.2005.07.011

McDonald, W. S., Miyamoto, K., Rivera, R., Kennedy, G., Almeida, B. S. V., Kingsbury, M. A., et al. (2020). Altered cleavage plane orientation with increased genomic aneuploidy produced by receptor-mediated lysophosphatidic acid (LPA) signaling in mouse cerebral cortical neural progenitor cells. Mol. Brain 13:169.

Möller, T., Contos, J. J., Musante, D. B., Chun, J., and Ransom, B. R. (2001). Expression and function of lysophosphatidic acid receptors in cultured rodent microglial cells. J. Biol. Chem. 276, 25946-25952. doi: 10.1074/jbc.m102691200

Moreno-Fernández, R. D., Nieto-Quero, A., ómez-Salas, F. J. G., Chun, J., EstivillTorrús, G., Rodríguez de Fonseca, F., et al. (2018). Effects of genetic deletion versus pharmacological blockade of the LPA(1) receptor on depressionlike behaviour and related brain functional activity. Dis. Model Mech. 11:dmm035519.

Nagai, J., Uchida, H., Matsushita, Y., Yano, R., Ueda, M., Niwa, M., et al. (2010). Autotaxin and lysophosphatidic acid1 receptor-mediated demyelination of dorsal root fibers by sciatic nerve injury and intrathecal lysophosphatidylcholine. Mol. Pain 6:78.

Nakajima, S., Gotoh, M., Fukasawa, K., Murofushi, H., and Murakami-Murofushi, K. (2018). 2-O-Carba-oleoyl cyclic phosphatidic acid induces glial proliferation through the activation of lysophosphatidic acid receptor. Brain Res. 1681, 44-51. doi: 10.1016/j.brainres.2017.12.031

Nam, S. M., Choi, S. H., Cho, H. J., Seo, J. S., Choi, M., Nahm, S. S., et al. (2020). Ginseng gintonin attenuates lead-induced rat cerebellar impairments during gestation and lactation. Biomolecules 10:385. doi: 10.3390/biom 10030385

Nogaroli, L., Yuelling, L. M., Dennis, J., Gorse, K., Payne, S. G., and Fuss, B. (2009). Lysophosphatidic acid can support the formation of membranous structures and an increase in MBP mRNA levels in differentiating oligodendrocytes. Neurochem. Res. 34, 182-193. doi: 10.1007/s11064-008-9772-z

Pan, H. L., Liu, B. L., Lin, W., and Zhang, Y. Q. (2016). Modulation of Nav1.8 by lysophosphatidic acid in the induction of bone cancer pain. Neurosci. Bull. 32, 445-454. doi: 10.1007/s12264-016-0060-7
Panetti, T. S. (2002). Differential effects of sphingosine 1-phosphate and lysophosphatidic acid on endothelial cells. Biochim. Biophys. Acta 1582, 190196. doi: 10.1016/s1388-1981(02)00155-5

Park, H., Kim, S., Rhee, J., Kim, H. J., Han, J. S., Nah, S. Y., et al. (2015). Synaptic enhancement induced by gintonin via lysophosphatidic acid receptor activation in central synapses. J. Neurophysiol. 113, 1493-1500. doi: 10.1152/jn.00667. 2014

Peng, J., Liu, F., Zheng, H., Wu, Q., and Liu, S. (2020). Long noncoding RNA ZFAS1 promotes tumorigenesis and metastasis in nasopharyngeal carcinoma by sponging miR-892b to up-regulate LPAR1 expression. J. Cell. Mol. Med. 24, 1437-1450. doi: $10.1111 / \mathrm{jcmm} .14823$

Piaton, G., Gould, R. M., and Lubetzki, C. (2010). Axon-oligodendrocyte interactions during developmental myelination, demyelination and repair. J. Neurochem. 114, 1243-1260.

Plastira, I., Bernhart, E., Joshi, L., Koyani, C. N., Strohmaier, H., Reicher, H., et al. (2020). MAPK signaling determines lysophosphatidic acid (LPA)-induced inflammation in microglia. J. Neuroinflammation 17:127.

Roberts, C., Winter, P., Shilliam, C. S., Hughes, Z. A., Langmead, C., Maycox, P. R., et al. (2005). Neurochemical changes in LPA(1) receptor deficient mice-a putative model of schizophrenia. Neurochem. Res. 30, 371-377. doi: 10.1007/ s11064-005-2611-6

Santos-Nogueira, E., Lopez-Serrano, C., Hernandez, J., Lago, N., Astudillo, A. M., Balsinde, J., et al. (2015). Activation of lysophosphatidic acid receptor type 1 contributes to pathophysiology of spinal cord injury. J. Neurosci. 35, 1022410235. doi: 10.1523/jneurosci.4703-14.2015

Savitz, S. I., Dhallu, M. S., Malhotra, S., Mammis, A., Ocava, L. C., Rosenbaum, P. S., et al. (2006). EDG receptors as a potential therapeutic target in retinal ischemia-reperfusion injury. Brain Res. 1118, 168-175. doi: 10.1016/j.brainres. 2006.05.060

Stankoff, B., Barron, S., Allard, J., Barbin, G., Noel, F., Aigrot, M. S., et al. (2002). Oligodendroglial expression of Edg-2 receptor: developmental analysis and pharmacological responses to lysophosphatidic acid. Mol. Cell. Neurosci. 20, 415-428. doi: 10.1006/mcne.2002.1129

Tabuchi, S., Kume, K., Aihara, M., and Shimizu, T. (2000). Expression of lysophosphatidic acid receptor in rat astrocytes: mitogenic effect and expression of neurotrophic genes. Neurochem. Res. 25, 573-582.

Takuwa, Y., Takuwa, N., and Sugimoto, N. (2002). The Edg family G proteincoupled receptors for lysophospholipids: their signaling properties and biological activities. J. Biochem. 131, 767-771. doi: 10.1093/oxfordjournals. jbchem.a003163

Thion, M. S., Ginhoux, F., and Garel, S. (2018). Microglia and early brain development: an intimate journey. Science 362, 185-189. doi: 10.1126/science. aat 0474

Uchida, H., Nagai, J., and Ueda, H. (2014). Lysophosphatidic acid and its receptors LPA1 and LPA3 mediate paclitaxel-induced neuropathic pain in mice. Mol. Pain 10:71.

Urbán, N., Blomfield, I. M., and Guillemot, F. (2019). Quiescence of adult mammalian neural stem cells: a highly regulated rest. Neuron 104, 834-848. doi: 10.1016/j.neuron.2019.09.026

Van Leeuwen, F. N., Olivo, C., Grivell, S., Giepmans, B. N., Collard, J. G., and Moolenaar, W. H. (2003). Rac activation by lysophosphatidic acid LPA1 receptors through the guanine nucleotide exchange factor Tiam1. J. Biol. Chem. 278, 400-406. doi: 10.1074/jbc.m210151200

van Tilborg, E., Heijnen, C. J., Benders, M. J., van Bel, F., Fleiss, B., Gressens, P., et al. (2016). Impaired oligodendrocyte maturation in preterm infants: potential therapeutic targets. Prog. Neurobiol. 136, 28-49. doi: 10.1016/j.pneurobio.2015. 11.002

Wheeler, N. A., Fuss, B., Knapp, P. E., and Zou, S. (2016). HIV-1 tat inhibits autotaxin lysophospholipase D activity and modulates oligodendrocyte differentiation. ASN Neuro 8:5. doi: 10.1177/1759091416669618

White, R., and Kraemer-Albers, E.-M. (2014). Axon-glia interaction and membrane traffic in myelin formation. Front. Cell. Neurosci. 7:284. doi: 10.3389/ fncel.2013.00284

Winter, J. N., Fox, T. E., Kester, M., Jefferson, L. S., and Kimball, S. R. (2010). Phosphatidic acid mediates activation of mTORC1 through the ERK signaling pathway. Am. J. Physiol. Cell Physiol. 299, C335-C344. 
Xie, W., Matsumoto, M., Chun, J., and Ueda, H. (2008). Involvement of LPA1 receptor signaling in the reorganization of spinal input through Abeta-fibers in mice with partial sciatic nerve injury. Mol. Pain 4:46.

Yang, X.-y, Zhao, E. Y., Zhuang, W.-x, Sun, F.-x, Han, H.-1, Han, H.-r, et al. (2015). LPA signaling is required for dopaminergic neuron development and is reduced through low expression of the LPA(1) receptor in a 6-OHDA lesion model of Parkinson's disease. Neurol. Sci. 36, 2027-2033. doi: 10.1007/s10072-015-2 295-x

Yao, J., Mu, Y., and Gage, F. H. (2012). Neural stem cells: mechanisms and modeling. Protein Cell 3, 251-261. doi: 10.1007/s13238-012-2033-6

Yu, L., Su, X., Li, S., Zhao, F., Mu, D., and Qu, Y. (2020). Microglia and their promising role in ischemic brain injuries: an update. Front. Cell. Neurosci. 14:211. doi: 10.3389/fncel.2020.00211

Yung, Y. C., Stoddard, N. C., Mirendil, H., and Chun, J. (2015). Lysophosphatidic acid signaling in the nervous system. Neuron 85, 669-682. doi: 10.1016/j. neuron.2015.01.009
Conflict of Interest: The authors declare that the research was conducted in the absence of any commercial or financial relationships that could be construed as a potential conflict of interest.

Publisher's Note: All claims expressed in this article are solely those of the authors and do not necessarily represent those of their affiliated organizations, or those of the publisher, the editors and the reviewers. Any product that may be evaluated in this article, or claim that may be made by its manufacturer, is not guaranteed or endorsed by the publisher.

Copyright (C) 2021 Xiao, Su, Gao, Li and Qu. This is an open-access article distributed under the terms of the Creative Commons Attribution License (CC BY). The use, distribution or reproduction in other forums is permitted, provided the original author(s) and the copyright owner(s) are credited and that the original publication in this journal is cited, in accordance with accepted academic practice. No use, distribution or reproduction is permitted which does not comply with these terms. 